\title{
Anti-inflammatory activity of a methanol extract from Ardisia tinctoria on mouse macrophages and paw edema
}

\author{
HUI-SEONG KIM ${ }^{1,4 *}$, JI-WON PARK ${ }^{2,4^{*}}$, OK-KYOUNG KWON ${ }^{3,4}$, JEA-HONG KIM $^{2}$, SEI-RYANG OH ${ }^{1,4}$, \\ HYEONG-KYU LEE ${ }^{1,5}$, TRAN THE BACH ${ }^{6}$, BUI HONG QUANG ${ }^{6}$ and KYUNG-SEOP AHN ${ }^{4}$
}

\begin{abstract}
${ }^{1}$ Biomolecular Science, University of Science and Technology, Daejeon 305-806; ${ }^{2}$ Department of Biotechnology, Korea University, Seoul 136-713; ${ }^{3}$ Department of Toxicology, College of Pharmacy, Chungnam National University, Daejeon 305-764; ${ }^{4}$ Natural Medicine Research Center and ${ }^{5}$ Targeted Medicine Research Center, Korea Research Institute of Bioscience and Biotechnology, Chungcheongbuk 363-883, Republic of Korea; ${ }^{6}$ Department of Botany, Institute of Ecology and Biological Resources,Vietnam Academy of Science and Technology, Hanoi 10307, Vietnam
\end{abstract}

Received June 24, 2013; Accepted January 22, 2014

DOI: $10.3892 / \mathrm{mmr} .2014 .1941$

\begin{abstract}
Ardisia tinctoria (AT) is a plant of the Myrsinaceae family. No studies on its anti-inflammatory effects have yet been reported. This study investigated the anti-inflammatory activity of AT. A non-cytotoxic methanol extract of AT inhibited the expression of inducible NO synthase (iNOS) and cyclooxygenase-2 (COX-2), leading to significantly reduced levels of nitric oxide $(\mathrm{NO})$ and prostaglandin $\mathrm{E}_{2}\left(\mathrm{PGE}_{2}\right)$ and of two proteins regulated by these, interleukin- $1 \beta$ (IL-1 $\beta$ ) and IL-6, in lipopolysaccharide (LPS)-stimulated RAW 264.7 macrophage cells. The thickness of paw edema induced in vivo in mice by carrageenan administration was effectively reduced by the AT extract. Translocation of the nuclear factor- $\kappa \mathrm{B}$ $(\mathrm{NF}-\kappa \mathrm{B})$ subunit 65 (p65) into the nucleus and phosphorylation of mitogen-activated protein kinase kinase (MEK) and extracellular signal-related kinase (ERK) were inhibited by the AT extract. Our results indicated that a methanol extract of AT downregulates the inflammatory response by blocking phosphorylation of MEK and ERK and activation of NF- $\kappa \mathrm{B}$. To the best of our knowledge, this is the first study of antiinflammatory effects of an AT extract, and demonstrates its potential in the treatment of inflammatory diseases.
\end{abstract}

Correspondence to: Dr Kyung-Seop Ahn, Natural Medicine Research Center, Korea Research Institute of Bioscience and Biotechnology, 30 Yeongudangi-ro, Ochang-eup, Chungcheongbuk 363-883, Republic of Korea

E-mail:ksahn@kribb.re.kr

*Contributed equally

Key words: inflammation, Ardisia tinctoria, MAPK, nitric oxid, $\mathrm{NF}-\kappa \mathrm{B}$

\section{Introduction}

Inflammation is a process associated with numerous diseases, which is regulated by a variety of immune cells and effector molecules. Nitric oxide (NO), prostaglandin $\mathrm{E}_{2}\left(\mathrm{PGE}_{2}\right)$, and pro-inflammatory cytokines are important mediators of macrophage-mediated inflammation $(1,2)$. Various in vitro and in vivo models have been used to measure the inhibitory effects of natural products on inflammatory cytokines and other inflammatory mediators $(3,4)$. Lipopolysaccharide (LPS) is a potent activator of macrophage cells, which produce a variety of pro-inflammatory mediators such as NO, prostaglandins, and cytokines $(5,6)$. Among these molecules, inducible nitric oxide synthase (iNOS) and cyclooxygenase-2 (COX-2) are two pro-inflammatory enzymes that play a critical role in inflammation. They produce the pro-inflammatory mediators $\mathrm{NO}$ and $\mathrm{PGE}_{2}$, respectively, thereby enhancing expression of pro-inflammatory cytokines, including interleukin-6 (IL-6) and IL-1 $\beta$ (7-9).

Expression of inflammatory cytokines and the genes that encode them can be regulated by activation of the transcription factor nuclear factor- $\kappa \mathrm{B}(\mathrm{NF}-\kappa \mathrm{B})$, which is crucially involved in chronic inflammatory diseases (10). Phosphorylation of mitogen-activated protein kinases (MAPKs), including MAP kinase kinase (MEK), extracellular signal-related kinase (ERK), p38, and C-Jun N-terminal kinase (JNK) is also a key factor in the inflammatory response (11). These events lead to the activation of macrophages, which consequently express genes encoding pro-inflammatory proteins such as iNOS and COX-2, and inflammatory cytokines (12).

Ardisia tinctoria (AT) is a plant of the Myrsinaceae family, which has traditionally been used as a natural black dye. Although some anti-inflammatory activities from other species of the genus Ardisia have been reported $(13,14)$, the biological activity of AT has yet not been studied.

In this study, to explore the anti-inflammatory properties of AT, we investigated the effect of an AT extract on the production of inflammatory mediators in a macrophage cell line, as well as in an in vivo model of carrageenan-induced paw edema. 


\section{Materials and methods}

Preparation of the AT extract from Aldisia tinctoria. Samples of the plant were collected from the Dak Glei District of Kon Tum Province, Dakman, Vietnam in 2009. The samples were identified as Aldisia tinctoria by Dr Tran The Bach at the Institute of Ecology and Biological Resources, Hanoi, Vietnam. A voucher specimen (KRIBB 0027029) was deposited in the herbarium of the Korea Research Institute of Bioscience and Biotechnology. AT (113 g) was treated with $\mathrm{MeOH}$ and sonicated several times at room temperature for 3 days to produce the extract (total, $10.3 \mathrm{~g}$ ).

Cell cultures. The RAW 264.7 murine macrophage cell line was cultured in Dulbecco's modified Eagle's medium (Gibco-BRL, Grand Island, NY, USA) supplemented with $10 \%$ (v/v) heat-inactivated fetal bovine serum (HyClone, Logan, UT, USA) and 1\% (w/v) of 100X antibiotic-antimycotic solution (cat. no. 15240-062; Invitrogen Life Technologies, Carlsbad, CA, USA), at $37^{\circ} \mathrm{C}$, in a $95 \%$ air and $5 \% \mathrm{CO}_{2}(\mathrm{v} / \mathrm{v})$ atmosphere.

Cell viability. The viability of cells treated with various concentrations of AT was monitored with a 3-(4,5-dimethylthiaxol-2yl)-2,5-diphenyltetrazolium bromide (MTT) (CAS\#298-93-1; Amresco, Solon, OH, USA) assay. MTT solution $(5 \mathrm{mg} / \mathrm{ml})$ was added to the cell supernatant at a final concentration of $0.5 \mathrm{mg} / \mathrm{ml}$. After $4 \mathrm{~h}$ of incubation at $37^{\circ} \mathrm{C}$, the medium was removed and dimethylsulfoxide (DMSO) was added to the 96-well plates. The optical density of formazan was measured at $570 \mathrm{~nm}$ using a Benchmark microplate reader (Bio-Rad Laboratories, Hercules, CA, USA). The level of formazan generated by untreated cells was used to define the $100 \%$ value.

Nitric oxide assay. RAW 264.7 cells were plated at a density of $5 \times 10^{5}$ cells $/ \mathrm{ml}$ in 96 -well plates, and incubated with or without LPS $(0.5 \mu \mathrm{g} / \mathrm{ml})$ in the absence or presence of various concentrations of AT extract for $24 \mathrm{~h}$. Nitrite accumulation in supernatants was assessed using the Griess reaction (15). Aliquots $(100 \mu \mathrm{l})$ of culture supernatants were mixed with equal volumes of Griess reagent $[0.1 \%(\mathrm{w} / \mathrm{v})$ $\mathrm{N}$-(1-naphthyl)-ethylenediamine, with $1 \%$ (w/v) sulfanilamide in $5 \%(\mathrm{v} / \mathrm{v})$ phosphoric acid] and incubated at room temperature for $10 \mathrm{~min}$. Absorbance was measured at $540 \mathrm{~nm}$ using a microplate reader, and a series of known sodium nitrite concentrations served as standards.

Enzyme-linked immunosorbent assay (ELISA). PGE 2 , IL-6, and IL-1 $\beta$ levels were quantified in the supernatants using the PGE $_{2}$ EIA kit (Cayman Chemical Co., Ann Arbor, MI, USA), and the IL-6- and IL- $1 \beta$-sensitive Quantikine Biosource ${ }^{\mathrm{TM}}$ ELISA kits (Invitrogen Life Technologies, Camarillo, CA, USA) according to the manufacturer's instructions.

Reverse transcription (RT)-PCR analysis. Total RNA was isolated from RAW 264.7 cells using TRIzol (Invitrogen Life Technologies), according to the manufacturer's instructions. The purified RNA was resuspended in diethylpyrocarbonate-treated water, and its integrity was confirmed by electrophoresis on an agarose-formaldehyde gel.cDNA was synthesized from total RNA that was previously treated with DNA-free DNase (Ambion Inc., Austin, TX, USA) according to indications of the supplier. RNA $(1 \mu \mathrm{g})$ was incubated with oligo(dT)18-mer (Bioneer Corp., Daejeon, Korea), RNase OUT (Invitrogen Life Technologies) and the Omniscript RT kit reagents (Qiagen, Hilden, Germany) for $60 \mathrm{~min}$ at $37^{\circ} \mathrm{C}$, following the indications of the supplier. The amplification of genes coding for iNOS (forward primer, 5'-GGA GCG ACT TGT GGA TTG TC-3' and reverse, 5'-GTG AGG GCT TGG CTG AGT GAG-3') and COX-2 (forward, 5'-GAA GTC TTT GGT CTG GTG CCT G-3' and reverse, 5'-GTC TGC TGG TTT GGA ATA GTT GC-3') was performed in the GeneAmp ${ }^{\circledR}$ PCR System 9700 (Applied Biosystems, Foster City, CA, USA) at $94^{\circ} \mathrm{C}$ for $30 \mathrm{sec}$, at $56^{\circ} \mathrm{C}$ for $30 \mathrm{sec}$, and at $72^{\circ} \mathrm{C}$ for $30 \mathrm{sec}$. As an internal control, the gene coding for $\beta$-actin was amplified using forward primer, 5'-AGG CTG TGC TGT CCC TGT ATG C-3' and reverse, 5'-ACC CAA GAA GGA AGG CTG GAA A-3'. The amplified products were resolved on a $1.2 \%(\mathrm{w} / \mathrm{v})$ agarose gel, stained with RedSafe (Intron Biotechnology, Seongnam-si, Korea), and photographed under ultraviolet light.

Western blot analysis. AT-treated and untreated RAW 264.7 cells were scraped and lysed in $100 \mu \mathrm{l}$ of lysis buffer containing protease inhibitors [50 mM Tris- $\mathrm{HCl}$ ( $\mathrm{pH} 7.4), 150 \mathrm{mM} \mathrm{NaCl}$, $1 \mathrm{mM}$ EDTA, $0.5 \%$ (v/v) NP-40, 0.1\% (w/v) SDS, 1 mM EGTA, $100 \mu \mathrm{g} / \mathrm{ml} \mathrm{PMSF}, 10 \mu \mathrm{g} / \mathrm{ml}$ pepstatin A, and $\left.100 \mu \mathrm{M} \mathrm{Na}_{3} \mathrm{VO}_{3}\right]$. Protein concentrations in supernatants were determined using the Bradford reagent (Bio-Rad Laboratories). Proteins (20 $\mu \mathrm{g}$ for each sample) were separated by electrophoresis at $100 \mathrm{~V}$ on a SDS-polyacrylamide gel for $90 \mathrm{~min}$, and transferred to PVDF membranes (Amersham Biosciences, Piscataway, NJ, USA). The membranes were blocked with $5 \%$ (w/v) non-fat dry milk dissolved in TBST buffer [10 mM Tris- $\mathrm{HCl}(\mathrm{pH} 7.5)$, $150 \mathrm{mM} \mathrm{NaCl}, 0.1 \%$ (v/v) Tween 20] overnight at $4^{\circ} \mathrm{C}$ and incubated with primary antibodies that recognize iNOS $(1: 1,000$ dilution; Enzo Clinical Labs Inc., Farmingdale, NY, USA); COX-2 (1:1,000; Santa Cruz Biotechnology, Inc., Santa Cruz, CA, USA); $\beta$-actin (1:1,000; Cell Signaling Technology, Inc., Boston, MA, USA); poly (ADP-ribose) polymerase (PARP), NF- $\kappa \mathrm{B}$ subunit 65 (p65), ERK 2, p38 MAPK and JNK1/3 (1:1,000; all from Santa Cruz Biochemicals); phosphorylated forms of p38 MAPK and JNK1/2 (1:1000; Enzo Clinical Labs Inc.) and phosphorylated forms of the NF- $\kappa \mathrm{B}$ inhibitor I $\kappa$ B- $\alpha$, MEK, ERK and total I $\kappa$ B- $\alpha$ (1:1,000; Cell Signaling Technology, Inc.). Immunoreactive bands were visualized using the ECL reagent (Amersham Pharmacia Biotech, Uppsala, Sweden) on a RAS-4000 mini film (Fujifilm, Tokyo, Japan). Densitometric values for each band were determined using the ImageJ software version 1.43 (National Institutes of Health), and were statistically analyzed.

Immunofluorescence. To analyze the nuclear localization of NF- $\kappa$ B, RAW 264.7 cells were maintained on Permanox plastic chamber slides (Nunc, Rochester, NY, USA) for $24 \mathrm{~h}$. Cells treated with AT for $1 \mathrm{~h}$ were incubated with LPS for $1 \mathrm{~h}$ as described by Park et al (16). Cells were fixed in ethanol at $4^{\circ} \mathrm{C}$ for $30 \mathrm{~min}$, and slides were washed three times with phosphate-buffered saline (PBS) and blocked with $3 \%(\mathrm{w} / \mathrm{v})$ 
bovine serum albumin (BSA) in PBS for an additional $30 \mathrm{~min}$. The slides were then incubated for $24 \mathrm{~h}$ at $4^{\circ} \mathrm{C}$ with rabbit polyclonal IgG antibodies targeting iNOS (1:200; Santa Cruz

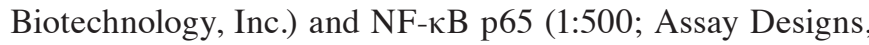
Ann Arbor, MI, USA). After washing to remove the excess primary antibody, the slides were further incubated with antirabbit Alexa Fluor 488-conjugated or Texas Red-conjugated secondary antibodies (Santa Cruz Biotechnology Inc.) for $2 \mathrm{~h}$ at room temperature, washed with PBS, and mounted using ProLong ${ }^{\circledR}$ Gold Antifade reagent containing 4',6-diamidino2-phenylindole (DAPI) (Invitrogen Life Technologies) for 5 min. Subsequently, the slides were coverslipped and visualized on a confocal laser scanning microscope (LSM510; Carl Zeiss, Jena, Germany), to localize the proteins of interest. The samples were photographed under the same exposure conditions and nuclei were quantified from the obtained images.

Animal care and carrageenan-induced paw edema. Pathogen-free female BALB/c mice (6 weeks old) were purchased from Koatech Co. (Seoul, Korea) and used after 1 week of quarantine and acclimatization. The mice were given sterilized tap water and standard rodent food. The experimental procedures were carried out in accordance with the NIH Guidelines for the Care and Use of Laboratory Animals and were approved by the institutional Animal Care and Use Committee of the Korea Research Institute of Bioscience and Biotechnology. The animals were handled in accordance with principles of the National Animal Welfare Law of Korea as previously described.

Carrageenan-induced paw inflammation was established based on a previously described method (18). Mice ( 20 g) were randomly selected and divided into groups of 5-6. AT was dissolved in PBS and administered at $40 \mathrm{mg} / \mathrm{kg}$ doses. The other groups were either orally administered with $5 \mathrm{mg} / \mathrm{kg}$ indomethacin (positive control) or injected with PBS (negative control). After $30 \mathrm{~min}$, the edema was induced by the injection of $20 \mu \mathrm{l}$ of $1 \% \mathrm{w} / \mathrm{v}$ carrageenan solution (Sigma-Aldrich, St. Louis, MO, USA) in PBS into the animal's left hind paw. Measurements of the paw volume were performed by means of a caliper immediately prior to the carrageenan injection and $4 \mathrm{~h}$ later. The paw thickness was determined by the difference between the final and initial thickness.

Statistical analysis. For statistical analysis, values were expressed as means \pm SEMs. Statistical significance was determined using the two-tailed Student's t-test for independent samples. $\mathrm{P}<0.05$ was considered to indicate statistically significant differences.

\section{Results}

Effects of AT extract on NO production in LPS-treated $R A W 264.7$ cells. To determine the inhibitory effect of AT on NO production, measured as nitrite levels, RAW 264.7 cells were treated with LPS. The AT extract markedly reduced nitrite levels in LPS-induced cells in a dose-dependent manner (Fig. 1A). As shown in Fig. 1B-D, expression levels of iNOS were determined by western blot analysis, immunofluorescence and RT-PCR. These assays showed that LPS treatment increased the expression of iNOS protein and
mRNA; however, pretreatment of cells with the AT extract attenuated the LPS-induced iNOS expression in a dose-dependent manner. This finding suggested that the AT extract inhibits NO production by inhibiting iNOS gene expression in LPS-stimulated RAW 264.7 cells.

Effects of AT extract on PGE 2 production in LPS-treated $R A W 264.7$ cells. The AT extract strongly inhibited the LPS-induced increase in $\mathrm{PGE}_{2}$ production (Fig. 2A) in a dose-dependent manner, while COX-2 protein (Fig. 2B) and mRNA (Fig. 2C) levels were reduced by treatment with the AT extract. Our results indicated that the AT extract has the potential to inhibit LPS-induced $\mathrm{PGE}_{2}$ and COX-2 expression in RAW 264.7 cells.

AT extract inhibits $I L-6$ and $I L-1 \beta$ release in $L P S$-treated $R A W 264.7$ cells. Cytokines are produced during the inflammatory process, and cytokine levels are indicative of the progression of inflammation. We used IL-6- and IL-1 $\beta$-sensitive ELISA kits to assess the levels of these cytokines in RAW 264.7 cells incubated with different concentrations of AT extract $(5,10,20$ and $30 \mu \mathrm{g} / \mathrm{ml})$ for $24 \mathrm{~h}$. LPS treatment caused an increase in the levels of IL-6 (Fig. 3A) and IL-1 $\beta$ (Fig. 3B) in RAW 264.7 cells, while their levels were reduced in a dose-dependent manner by exposure to AT. Treatment with the AT extract did not affect the viability of cultured RAW 264.7 cells (Fig. 3C).

Inhibitory effect of $A T$ extract on $N F-\kappa B$ activation in LPS-treated RAW 264.7 cells. We examined the effect of the AT extract on LPS-induced NF- $\kappa \mathrm{B}$ activation. $\mathrm{NF}-\kappa \mathrm{B}$, which induces both iNOS and COX-2, is translocated to the nucleus following phosphorylation and subsequent degradation of IкB- $\alpha$. Treatment of RAW 264.7 cells with AT for $1 \mathrm{~h}$ markedly inhibited the nuclear level of the NF- $\kappa \mathrm{B}$ p65 subunit induced by LPS (Fig. 4A). Confocal microscopy showed $\mathrm{NF}-\kappa \mathrm{B}$ translocation to the nucleus in response to LPS stimulation (Fig. 4B). Our results suggested that AT inhibits the expression of pro-inflammatory enzymes such as iNOS and $\mathrm{COX}-2$, by blocking the translocation of $\mathrm{NF}-\kappa \mathrm{B}$ to the nucleus.

Inhibitory effect of AT extract on phosphorylation of MEK and ERK in LPS-treated RAW 264.7 cells. We examined the effect of the AT extract on LPS-induced phosphorylation of MEK, ERK, JNK and p38 MAPK. Western blotting assays were performed after treating the cells with LPS $(0.5 \mu \mathrm{g} / \mathrm{ml})$ for $0,5,15$ and $30 \mathrm{~min}$. Phosphorylation of these proteins was clearly induced only at $30 \mathrm{~min}$ of LPS treatment. The AT extract inhibited the LPS-induced phosphorylation of ERK in a time-dependent manner, while reduced phosphorylation of MEK was observed at $40 \mathrm{~min}$ of LPS treatment (Fig. 5).

Effect of AT extract on carrageenan-induced paw edema in mice. Edema was induced by injection of carrageenan into the paw of six mice. As shown in Fig. 6, the injection of carrageenan for $4 \mathrm{~h}$ significantly increased the thickness of paw edema. Indomethacin, a non-steroidal anti-inflammatory drug commonly used in the clinic, was used as a positive control for the reduction in paw edema thickness. Pre-treatment with $5 \mathrm{mg}$ / $\mathrm{kg}$ of indomethacin effectively and significantly reduced paw 

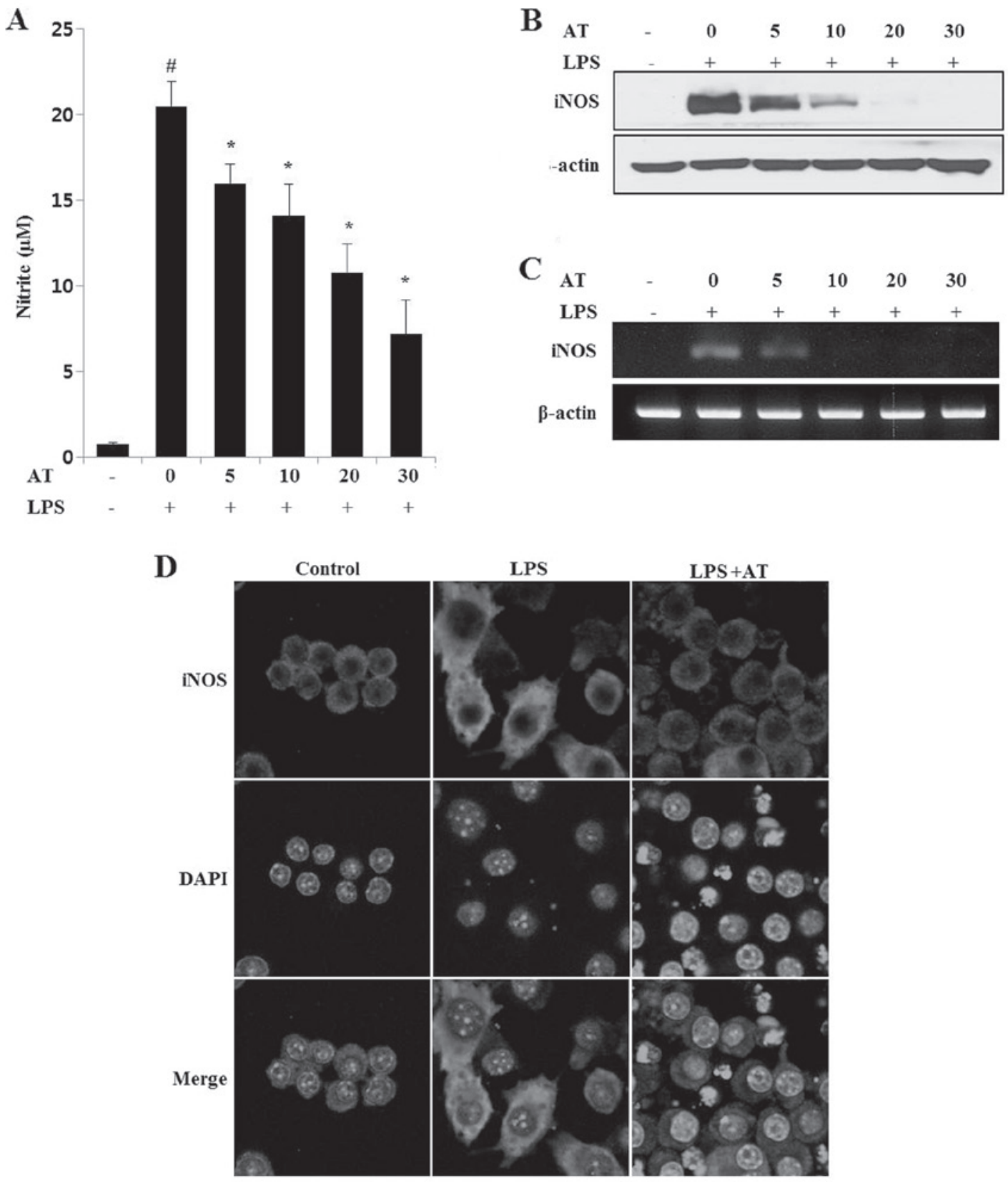

Figure 1. Lipopolysaccharide (LPS)-induced nitric oxide (NO) production and nitric oxide synthase (iNOS) expression are inhibited by Ardisia tinctoria (AT) extract in RAW 264.7 cells. (A) RAW 264.7 cells were treated with AT extract $(5,10,20$ and $30 \mu \mathrm{g} / \mathrm{ml})$ for $1 \mathrm{~h}$, and with LPS $(0.5 \mu \mathrm{g} / \mathrm{ml})$ for 6 or $24 \mathrm{~h}$. The supernatant was collected at $24 \mathrm{~h}$, and nitrite concentrations were measured using the Griess reaction. Three independent experiments were performed, and the data are presented as means \pm SEM. ${ }^{\#} \mathrm{P}<0.05 ;{ }^{*} \mathrm{P}<0.05 ;{ }^{* *} \mathrm{P}<0.01$; and ${ }^{* * *} \mathrm{P}<0.001$ compared to control $\left({ }^{*}\right)$ or cells treated with LPS alone $\left({ }^{*, * * * * * *}\right)$. (B) iNOS mRNA and (C) iNOS protein levels were measured with reverse transcription (RT)-PCR and western blotting assays, respectively, using $\beta$-actin as an internal control. (D) Immunocytochemical analysis of iNOS expression. After fixation, cells were stained with Alexa 488. Nuclei were visualized using DAPI, and observed at x400 magnification. Merge, superposition of the DAPI and iNOS fields; Control, untreated cells; LPS, LPS ( $0.5 \mu \mathrm{g} / \mathrm{ml})$ treatment; AT, AT extract $(40 \mu \mathrm{g} / \mathrm{ml})$ and LPS treatment.

edema thickness. Similarly, pre-administration of AT $(40 \mathrm{mg} /$ $\mathrm{kg}$ ) markedly inhibited (by 58.8\%) carrageenan-induced paw edema thickness.

\section{Discussion}

In the present study, we evaluated the anti-inflammatory effect of AT both in vivo and in vitro. To understand the related molecular mechanisms, we investigated the production of $\mathrm{NO}$, $\mathrm{PGE}_{2}$, IL-1 $\beta$ and IL-6, the expression of iNOS and COX-2, and the activation of the NF- $\mathrm{kB}$ and MAPK signaling pathway proteins in response to AT.

Macrophages are an important component of the human immune defense system. During the progress of inflammation, macrophages actively participate in inflammatory responses by releasing the pro-inflammatory cytokines IL- $1 \beta$ and IL-6, as well as other inflammatory factors, such as $\mathrm{NO}$ and $\mathrm{PGE}_{2}$, which recruit additional immune cells to the sites of infection or tissue injury (1). In this study, we validated the effects of AT on the secretion of $\mathrm{NO}$ and $\mathrm{PGE}_{2}$ in the supernatants of 
A

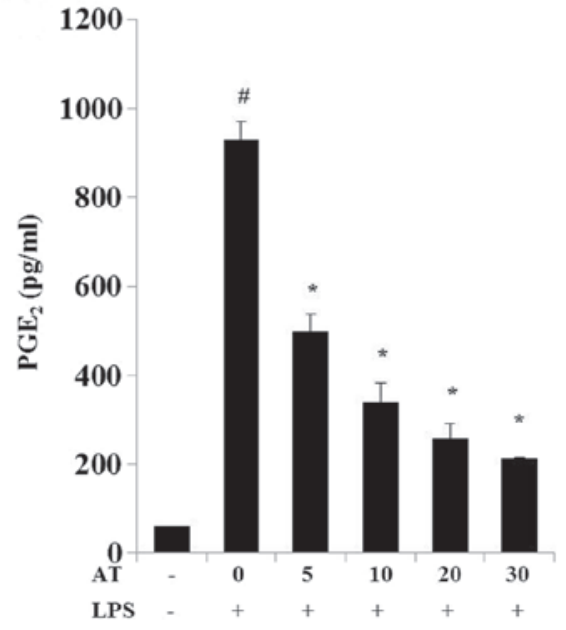

B

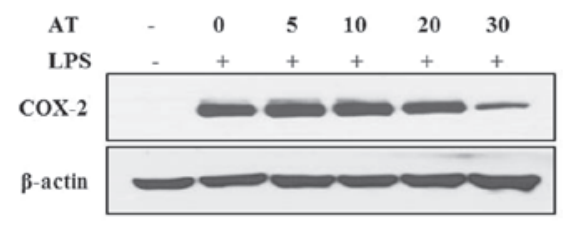

C

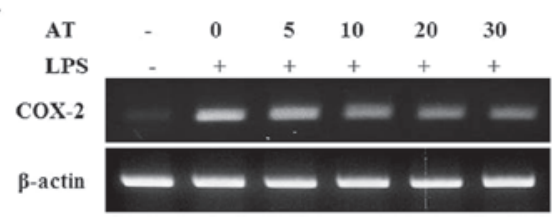

Figure 2. Ardisia tinctoria (AT) extract inhibits lipopolysaccharide (LPS)-induced prostaglandin $\mathrm{E}_{2}\left(\mathrm{PGE}_{2}\right)$ production and cyclooxygenase-2 (COX-2) expression in RAW 264.7 cells. (A) RAW 264.7 cells were pretreated with AT extract $(5,10,20$ and $30 \mu \mathrm{g} / \mathrm{ml})$ for $1 \mathrm{~h}$ and with LPS $(0.5 \mu \mathrm{g} / \mathrm{ml})$ for 6 or $24 \mathrm{~h}$. The supernatant was collected at $24 \mathrm{~h}$ to measure $\mathrm{PGE}_{2}$ concentration using an enzyme immunoassay. Data are presented as means \pm SEM of three independent experiments. ${ }^{*} \mathrm{P}<0.05 ;{ }^{*} \mathrm{P}<0.05 ;{ }^{* * *} \mathrm{P}<0.01$ and ${ }^{* * * *} \mathrm{P}<0.001$ compared to control $\left(^{*}\right)$ or cells treated with LPS alone $\left({ }^{*},{ }^{* *, * * * *}\right)$. (B) COX-2 mRNA and (C) COX-2 protein levels were measured with reverse transcription (RT)-PCR and western blotting assays, respectively, using $\beta$-actin as an internal control. Representative results of four independent experiments are shown.
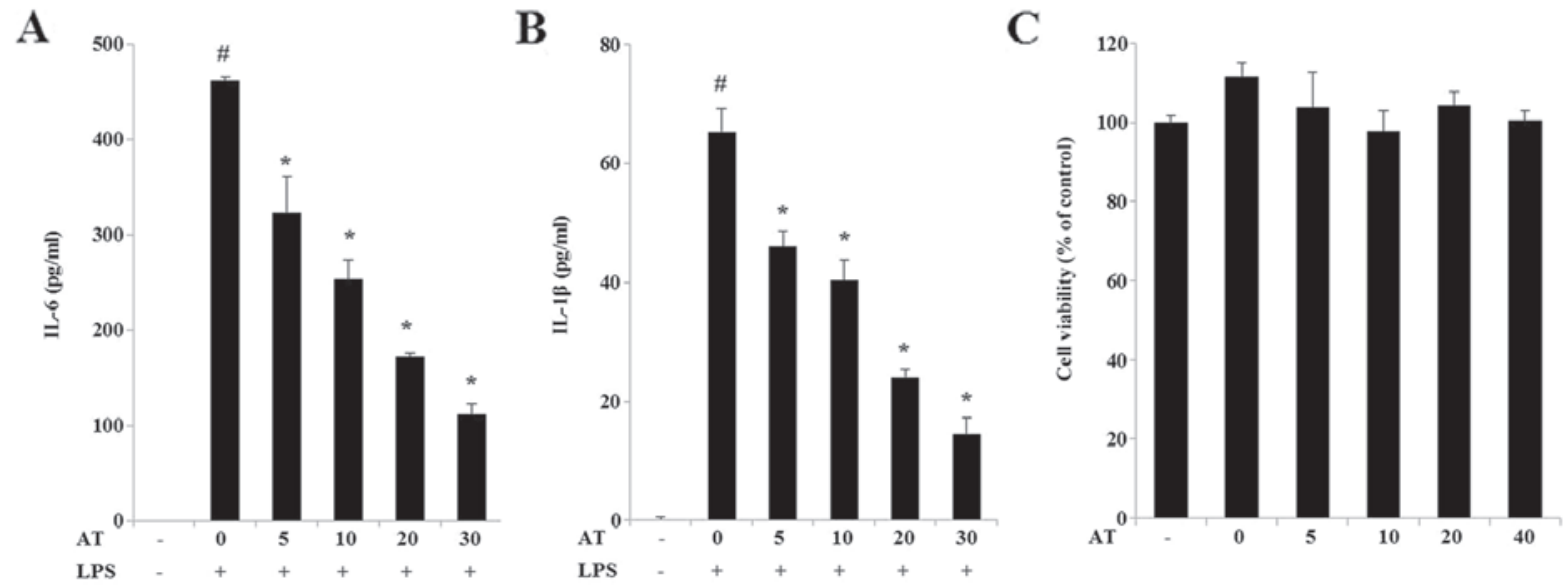

Figure 3. Ardisia tinctoria (AT) extract inhibits IL-1 $\beta$ and IL-6 production in lipopolysaccharide (LPS)-treated RAW 264.7 cells. (A) IL-1 $\beta$ and (B) IL-6 cytokines were measured using enzyme-linked immunosorbent assay (ELISA) on the supernatants of treated cells. RAW 264.7 cells were treated with 0-30 $\mu \mathrm{g} / \mathrm{ml}$ AT extract for $1 \mathrm{~h}$, and continuously incubated with LPS $(0.5 \mu \mathrm{g} / \mathrm{ml})$ for an additional $18 \mathrm{~h}$. (C) AT extract treatment $(0-40 \mu \mathrm{g} / \mathrm{ml})$ did not affect the viability of cultured RAW 264.7 cells. Data are presented as means \pm SEM of three samples. ${ }^{*} \mathrm{P}<0.05 ;{ }^{*} \mathrm{P}<0.05 ;{ }^{* *} \mathrm{P}<0.01$ and ${ }^{* * *} \mathrm{P}<0.001$ compared to control $\left({ }^{\sharp}\right)$ or cells treated with LPS alone $(*, * * * * * *)$.

cultured RAW 264.7 cells treated with LPS. Pre-treatment with AT reduced the LPS-induced secretion of $\mathrm{NO}$ and $\mathrm{PGE}_{2}$. In addition, AT treatment significantly inhibited the production of the cytokines IL-1 $\beta$ and IL- 6 . AT also effectively inhibited the mRNA and protein expression of iNOS, which triggers the effector molecule NO (19) and of COX-2, which catalyzes the production of $\mathrm{PGE}_{2}(20)$.

LPS-induced secretion and expression of inflammatory mediators in RAW 264.7 macrophage cells is activated by diverse intracellular signals, including the $\mathrm{NF}-\kappa \mathrm{B}$ and MAP kinase pathways (16). Two NF- $\kappa \mathrm{B}$ pathways exist, and it is believed that these play distinct and important roles in the innate and the acquired immune response (21). NF- $\kappa \mathrm{B}$ has been shown to be a key transcription factor that activates several cellular signal transduction pathways involved in the production of iNOS, COX-2 and various cytokines $(22,23)$. Immunofluorescence visualizations suggested that AT inhibits iNOS and COX-2 expression through reduction of the nuclear levels of translocated NF- $\mathrm{kB}$ p65 in LPS-stimulated RAW 264.7 macrophage cells. MAPK family members, including MEK, ERK, JNK and the MAPK p38 subunit, are also activated and phosphorylated following LPS treatment (24-26). In our study, LPS-stimulated phosphorylation of MEK and ERK was inhibited by pretreatment with AT. Moreover, we tested the effects of AT on acute inflammation in mice using the carrageenan-induced paw edema model. The latter has been established as a valid model for studying inflammatory states and screening of components for anti-inflammatory activity. A reduction in edema thickness is a good indicator of the protective action of anti-inflammatory agents (27). AT (40 mg/kg) 
A

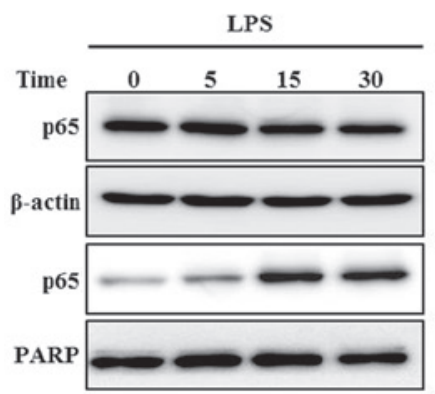

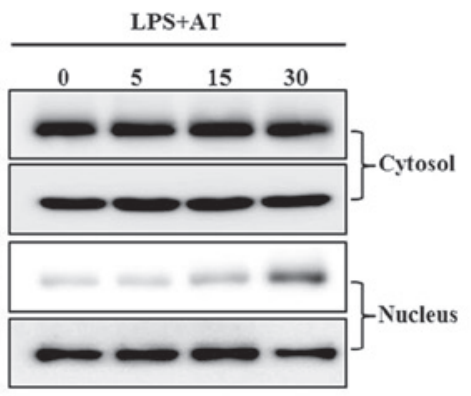

B

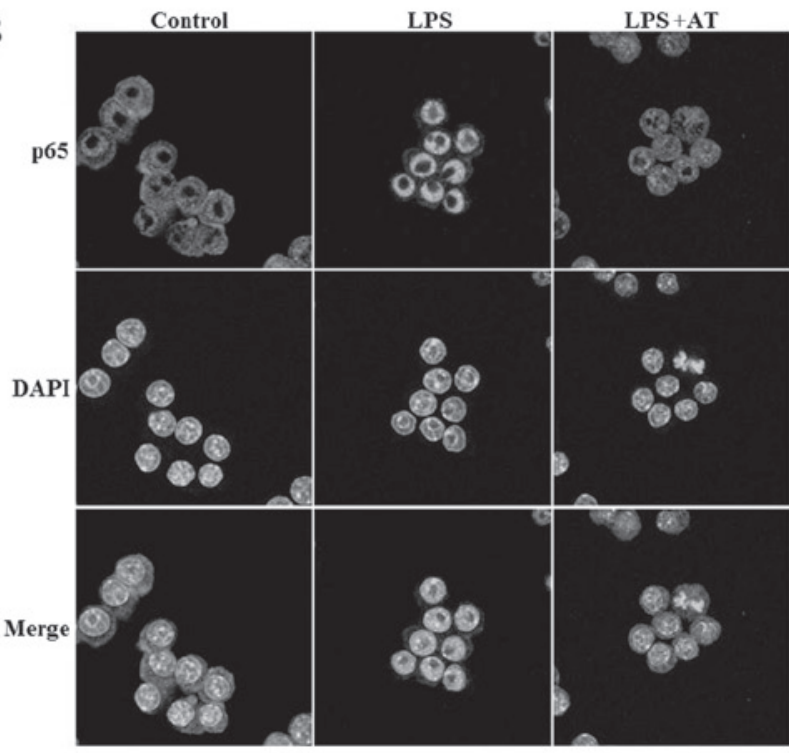

Figure 4. Ardisia tinctoria (AT) extract inhibits the translocation of nuclear factor- $\mathrm{kB}$ (NF- $\mathrm{\kappa B}$ ) to the nucleus in lipopolysaccharide (LPS)-treated RAW 264.7 cells. Cells were treated with AT extract ( $30 \mu \mathrm{g} / \mathrm{ml}$ ) for $1 \mathrm{~h}$, then with LPS for $1 \mathrm{~h}$ hour, and the cytosol and nuclear fractions were separated. (A) Translocation of NF- $\kappa \mathrm{B}$ p65 to the nucleus, as determined by western blot. Antibodies targeting $\beta$-actin and poly (ADP-ribose) polymerase (PARP) were used as internal controls for the western blot analysis of cytosolic and nuclear proteins, respectively. (B) Immunocytochemical examination of NF- $\mathrm{kB}$ translocation. After fixation, the cells were stained with Alexa 488. Nuclei were visualized using DAPI, and observed at x400 magnification. Merge, superposition of the DAPI and iNOS fields; Control, untreated cells; LPS, LPS $(0.5 \mu \mathrm{g} / \mathrm{ml})$ treatment; AT, AT extract $(40 \mu \mathrm{g} / \mathrm{ml})$ and LPS treatment. Representative results of three independent experiments are shown.

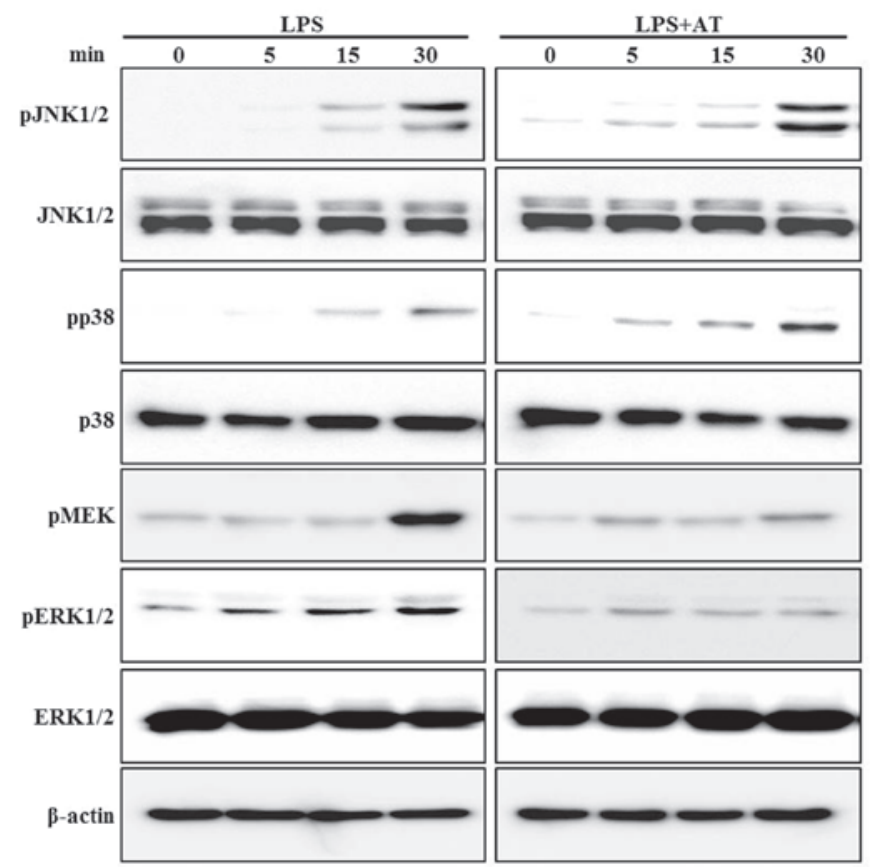

Figure 5. Ardisia tinctoria (AT) extract reduces the levels of phosphorylated (p) mitogen-activated protein kinase (MAPK) molecules in lipopolysaccharide (LPS)-treated RAW 264.7 cells. Cells were pretreated with AT extract $(30 \mu \mathrm{g} / \mathrm{ml})$ for $1 \mathrm{~h}$, and then with LPS $(0.5 \mu \mathrm{g} / \mathrm{ml})$ for $0,5,15$ and 30 min. MEK, MAP kinase kinase; ERK1/2, extracellular signal-related kinase $1 / 2$; JNK1/2, C-Jun N-terminal kinase $1 / 2$ and p38, MAPK subunit 38. Representative results of three independent experiments are shown.

inhibited the thickness of paw edema after $4 \mathrm{~h}$ of carrageenan treatment.

In summary, this study demonstrated that a methanol extract of AT may possess anti-inflammatory effects, since it can

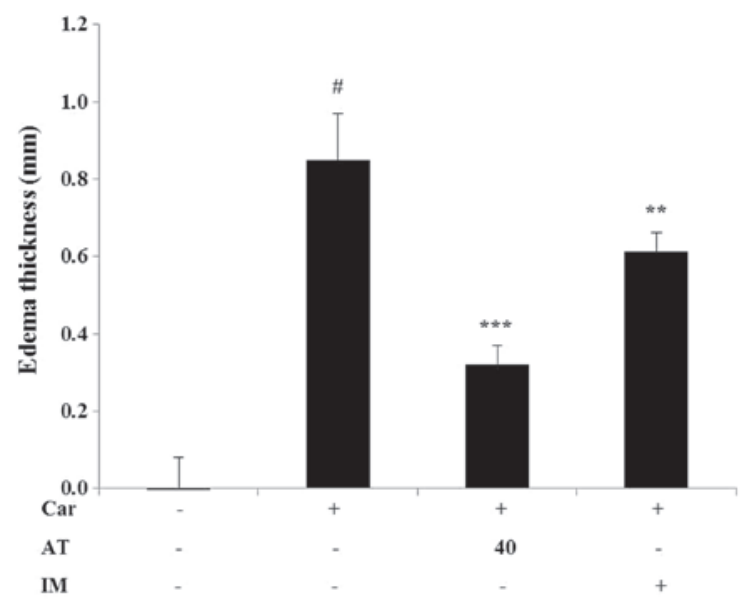

Figure 6. Carrageenan-induced paw edema is inhibited by Ardisia tinctoria (AT) extract. Pre-administration of AT $(40 \mathrm{mg} / \mathrm{kg})$ markedly reduced the thickness of the carrageenan-induced paw edema. Data are shown as inhibition percentage (IP) of edema thickness \pm SE, with IP calculated as $40.1 \%$. Car, $20 \mu 1$ of $1 \% \mathrm{w} / \mathrm{v}$ carrageenan solution; IM, $5 \mathrm{mg} / \mathrm{ml}$ indomethacin. ${ }^{*} \mathrm{P}<0.05 ;{ }^{*} \mathrm{P}<0.05 ;{ }^{* *} \mathrm{P}<0.01$; and ${ }^{* * * *} \mathrm{P}<0.001$ compared to control $\left({ }^{*}\right)$ or cells treated with Car alone $(*, * *, * * *)$.

affect the production of $\mathrm{NO}, \mathrm{PGE}_{2}$, IL-1 $1 \beta$ and IL-6, as well as the mRNA and protein expression of iNOS and COX-2. These effects may be mediated by the inhibition of LPS-induced NF- $\mathrm{KB}$ activation and the phosphorylation of MEK and ERK, which were observed in vitro in the RAW 264.7 macrophage cells.

\section{Acknowledgements}

This study was supported by grants from FGC (no. 1011231) and KGM (no. 1221312) awarded to the Korea Research 
Institute of Bioscience and Biotechnology (KRIBB) of the Republic of Korea.

\section{References}

1. Bosca L, Zeini M, Traves PG and Hortelano S: Nitric oxide and cell viability in inflammatory cells: a role for $\mathrm{NO}$ in macrophage function and fate. Toxicology 208: 249-258, 2005.

2. Moncada S: Nitric oxide: discovery and impact on clinical medicine. J R Soc Med 92: 164-169, 1999.

3. Tripathi P, Tripathi P, Kashyap L and Singh V: The role of nitric oxide in inflammatory reactions. FEMS Immunol Med Microbiol 51: 443-452, 2007.

4. Winter CA, Risley EA and Nuss GW: Carrageenin-induced edema in hind paw of the rat as an assay for antiiflammatory drugs. Proc Soc Exp Biol Med 111: 544-547, 1962.

5. Fujihara M, Muroi M, Tanamoto K, Suzuki T, Azuma H and Ikeda H: Molecular mechanisms of macrophage activation and deactivation by lipopolysaccharide: roles of the receptor complex. Pharmacol Ther 100: 171-194, 2003.

6. Kuroda E and Yamashita U: Mechanisms of enhanced macrophage-mediated prostaglandin $\mathrm{E} 2$ production and its suppressive role in Th1 activation in Th2-dominant BALB/c mice. J Immunol 170: 757-764, 2003.

7. Moncada S, Palmer RM and Higgs EA: Nitric oxide: physiology, pathophysiology, and pharmacology. Pharmacol Rev 43: 109-142, 1991.

8. Elder DJ, Halton DE, Hague A and Paraskeva C: Induction of apoptotic cell death in human colorectal carcinoma cell lines by a cyclooxygenase-2 (COX-2)-selective nonsteroidal anti-inflammatory drug: independence from COX-2 protein expression. Clin Cancer Res 3: 1679-1683, 1997.

9. Dinarello CA: Immunological and inflammatory functions of the interleukin-1 family. Annu Rev Immunol 27: 519-550, 2009.

10. Makarov SS: NF-kappaB as a therapeutic target in chronic inflammation: recent advances. Mol Med Today 6: 441-448, 2000

11. Guha M and Mackman N: LPS induction of gene expression in human monocytes. Cell Signal 13: 85-94, 2001.

12. Bresnihan B: Pathogenesis of joint damage in rheumatoid arthritis. J Rheumatol 26: 717-719, 1999.

13. de Mejia EG and Ramirez-Mares MV: Ardisia: health-promoting properties and toxicity of phytochemicals and extracts. Toxicol Mech Methods 21: 667-674, 2011.

14. Hamsin DE, Hamid RA, Yazan LS, Taib CN and Ting YL: The hexane fraction of Ardisia crispa Thunb. A. DC. roots inhibits inflammation-induced angiogenesis. BMC Complement Altern Med 13: 5, 2013
15. Kim H, Lee HS, Chang KT, Ko TH, Baek KJ and Kwon NS Chloromethyl ketones block induction of nitric oxide synthase in murine macrophages by preventing activation of nuclear factor-kappa B. J Immunol 154: 4741-4748, 1995.

16. Park JW, Kwon OK, Jang HY, et al: A leaf methanolic extract of Wercklea insignis attenuates the lipopolysaccharide-induced inflammatory response by blocking the $\mathrm{NF}-\kappa \mathrm{B}$ signaling pathway in RAW 264.7 macrophages. Inflammation 35: 321-331, 2012.

17. Yuk JE, Lee MY, Kwon OK, et al: Effects of astilbic acid on airway hyperresponsiveness and inflammation in a mouse model of allergic asthma. Int Immunopharmacol 11: 266-273, 2011.

18. Henriques MG, Silva PM, Martins MA, et al: Mouse paw edema. A new model for inflammation? Braz J Med Biol Res 20: 243-249, 1987.

19. Connelly L, Palacios-Callender M, Ameixa C, Moncada S and Hobbs AJ: Biphasic regulation of NF- $\mathrm{NB}$ activity underlies the pro- and anti-inflammatory actions of nitric oxide. J Immunol 166: 3873-3881, 2001.

20. Cuccurullo C, Fazia ML, Mezzetti A and Cipollone F: COX-2 expression in atherosclerosis: the good, the bad or the ugly? Curr Med Chem 14: 1595-1605, 2007.

21. Bonizzi $\mathrm{G}$ and Karin M: The two NF- $\kappa$ B activation pathways and their role in innate and adaptive immunity. Trends Immunol 25: 280-288, 2004.

22. Hayden MS and Ghosh S: Signaling to NF-кB. Genes Dev 18 2195-2224, 2004

23. Marks-Konczalik J, Chu SC and Moss J: Cytokine-mediated transcriptional induction of the human inducible nitric oxide synthase gene requires both activator protein 1 and nuclear factor $\kappa$ B-binding sites. J Biol Chem 273: 22201-22208, 1998.

24. Geppert TD, Whitehurst CE, Thompson P and Beutler B: Lipopolysaccharide signals activation of tumor necrosis factor biosynthesis through the ras/raf-1/MEK/MAPK pathway. Mol Med 1: 93-103, 1994.

25. Hambleton J, Weinstein SL, Lem L and DeFranco AL: Activation of c-Jun N-terminal kinase in bacterial lipopolysaccharide-stimulated macrophages. Proc Natl Acad Sci USA 93: 2774-2778, 1996.

26. Han J, Lee JD, Bibbs L and Ulevitch RJ: A MAP kinase targeted by endotoxin and hyperosmolarity in mammalian cells. Science 265: 808-811, 1994.

27. Handy RL and Moore PK: A comparison of the effects of L-NAME, 7-NI and L-NIL on carrageenan-induced hindpaw oedema and NOS activity. Br J Pharmacol 123: 1119-1126, 1998. 